\title{
Rank reversal in females' hierarchy in semi-free ranging capuchin monkeys (Cebus apella)
}

FAlótico, Tiago; VeRdeRANe, Michele P.; Resende, Briseida D.; OTTONI, Eduardo B. \& IZAR, Patrícia

- Rank reversal was the result of a coalition among three females that defeated the alpha female

-The former alpha female ( $J$ anete) could not hold her position probably because

1. she had not established strong bonds with the alpha male and the other females, as indicated by grooming relationships (e.g. Janson, 1990, di Bitteti, 1997, Parr et al. 1997, Ferreira \& Izar, in prep.)

2. she was initially supported by an adult male, Eli, who latter left the group, and so she lost her main supporter

3. she was in the end of gestation, what may have handicapped her during the fights

- One factor that may have contributed to the rank reversal process was the transition to adulthood and pregnancy of the females Cisca and Vavá

-During the period of rank reversal, high frequencies of agonism were accompanied by high rates of grooming, reinforcing the hypothesis of grooming as a reassuring behavior (Dunbar, 1991)

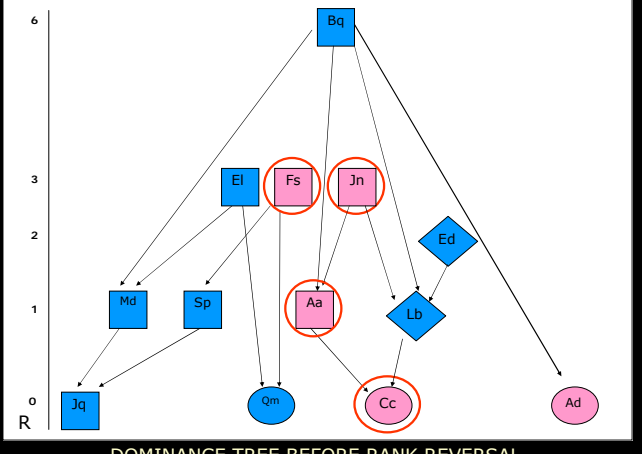

DOMINANCE TREE BEFORE RANK REVERSAL

Janete (Jn) and Física (Fs) seemed to have the same rank. But only Janete had a direct dominance relationship with Ana (Aa). Note also that Cisca (Cc) was a low ranking individual.

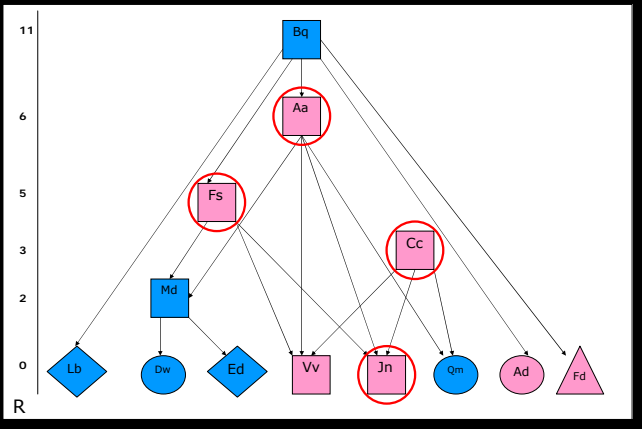

DOMINANCE TREE AFTER RANK REVERSAL

Janete (Jn), became a low ranking female, being directly dominated by Física ( $\mathrm{Fs})$, Ana $(\mathrm{Aa})$ and Cisca $(\mathrm{Cc})$. Vavá (Vv) that did not appear in the first
the same females as Janete.

Ana became the dominant female; however, she has not a direc dominance relationship with $\mathrm{Fs}$ or $\mathrm{Cc}$, an adult female who rose to the top of the hierarchy. And the
female, made a ride up to the hierarchy.

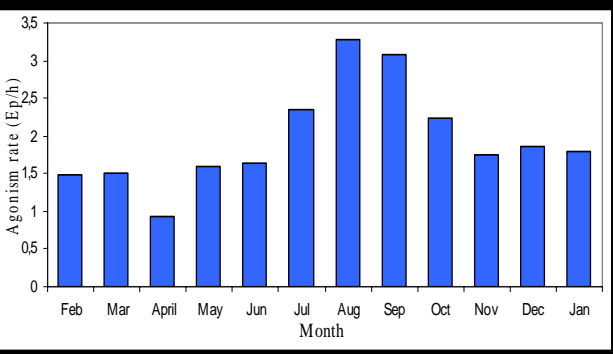

AGONISM RATES FEBRUARY/2002 TO JANUARY/2003

On July, 2002, there was an increase in agonism rate that lasted until October, when it lowered to the initial levels.

Frequencies of agonistic episodes varied significantly across the study period $\left(\chi^{2}=153,8 ; \mathrm{df}=11 ; \mathrm{p}<0,0001\right)$. Standard October.

\begin{tabular}{l} 
Method \\
We observed a group of 17-19 capuchins (Cebus apella) in Tietê \\
Ecological Park at São Paulo-Brazil, between March and \\
September/2002. \\
Data on grooming and interindividual distances (contact, 1, 5 and 10 \\
meters) were collected by Focal-scan method, and on aggressive \\
behavior were collected by All Occurrences method (Altmann, 1974). \\
\hline
\end{tabular}

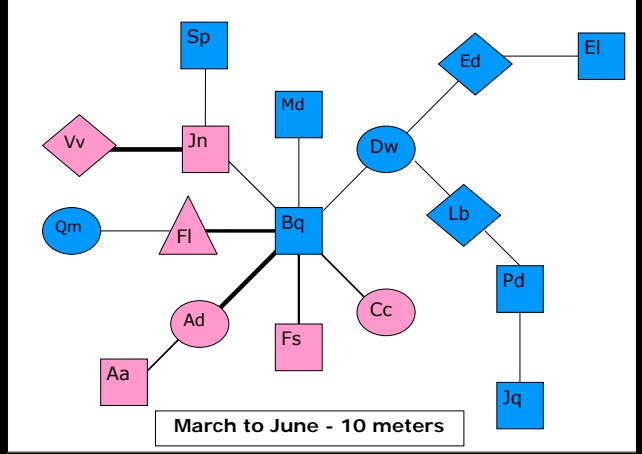

MINIMUM SPANNING TREE OF THE FIRST PERIOD

On the period before the fights and the reversion, the alpha male (Bq) was the centre of the group, with almost all females directly connected to $\mathrm{Bq}$ through her daughter $\mathrm{Ada}(\mathrm{Ad})$.

Janete's (Jn) connection to $\mathrm{Bq}$ was the weakest between the females that were connected to the alpha male.

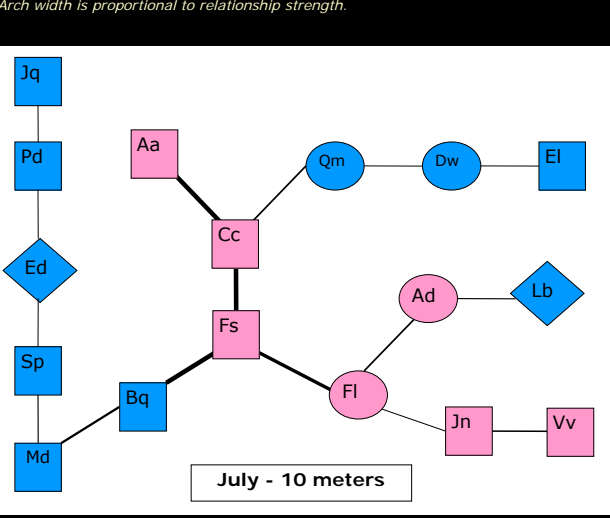

MINIMUM SPANNING TREE OF THE SECOND PERIOD During the fight period, the females that formed the coalition gainst the alpha Jn were directly connected - Cc, Aa and Fs. was connected to her daughter $V \mathrm{~V}$, and they were apart of the
other adult females. Jn and $\mathrm{V} v$ were the target of the threatening from the coalition $C_{1}$

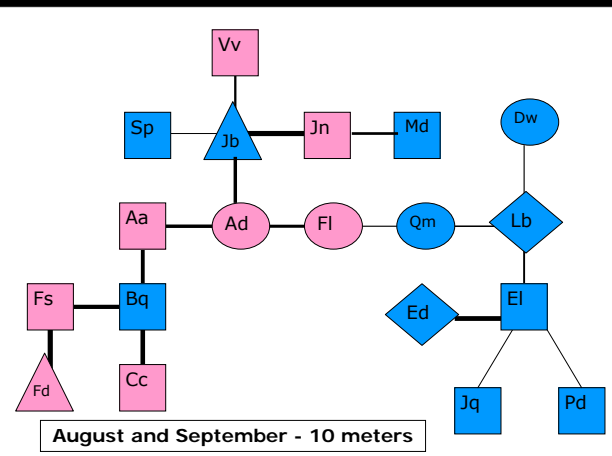

MINIMUM SPANNING TREE OF THE THIRD PERIOD

During this period, only the females that formed the coalition are directly connected to the alpha male $(\mathrm{Bq})$. The former alph born son Jujuba (Jb) and to Medeiros (Md), a castrated adu male. Vavá $(\mathrm{Vv})$ is only connected to Jb, her brother.
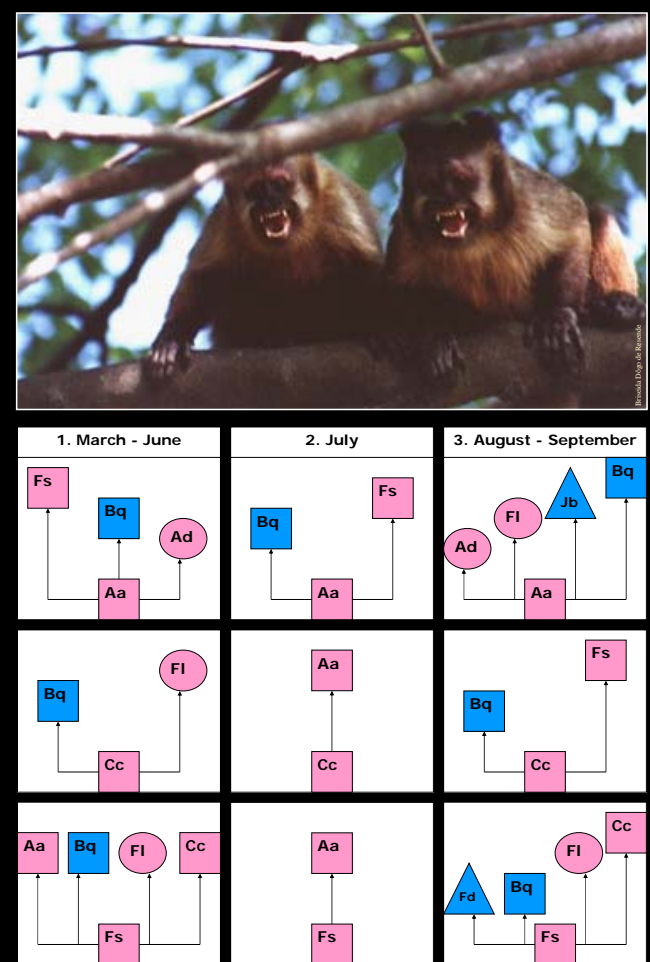

3. August - September
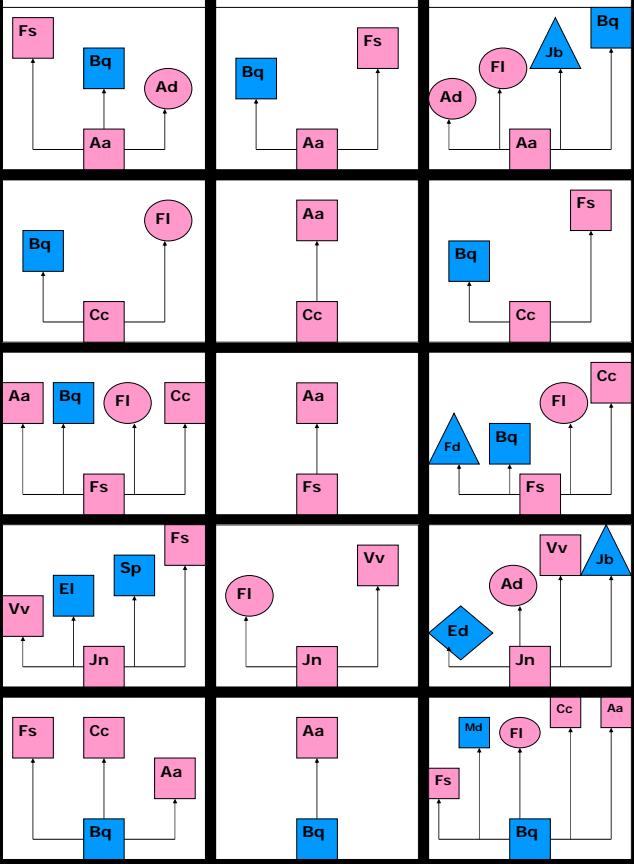

Aa

Fs

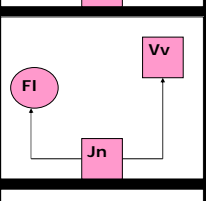

(C)

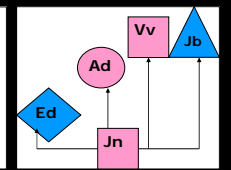

Aa

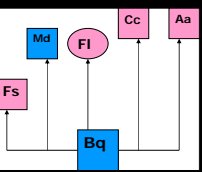

FIRST ARCHS OF THE SHORTEST DIRECT TREES OF GROOMING

During the first period, all females but Janete groomed and were groomed by the alpha male. Física and Ana groomed each other. Janete groomed two other adult males.

On the second period, during the peak of agonistic behaviors, Ana However, Ana groomed only Fs and Bq. Janete groomed only her daughter Vavá and Física 's daughter, Filó (FI). The third period had two newborn infants, Jujuba (Jb) and Frida (Fd), Janete's and Física's offspring, respectively. They are Despite her new infant, Jn was not groomed by any other female. All females but Jn groomed and were groomed by the alpha male. The length of the trees $(L)$ varied significantly across the three periods (Kruskal-Wallis Test, $\chi^{2}=22,96$, df second period (during the fights) $L$ was significantly smaller than first period (Mann-Whitney, $U=0,001, p=0,001$ ) and third period (Mann-Whitney, $U=3,0 \quad p=0,001$ ), showing that the grooming
relationships were stronger during the period of high agonism. The root of the branch is the individual that performs the grooming. There are only the
first branch of the adults females involved in the fights and the alpha male trees.
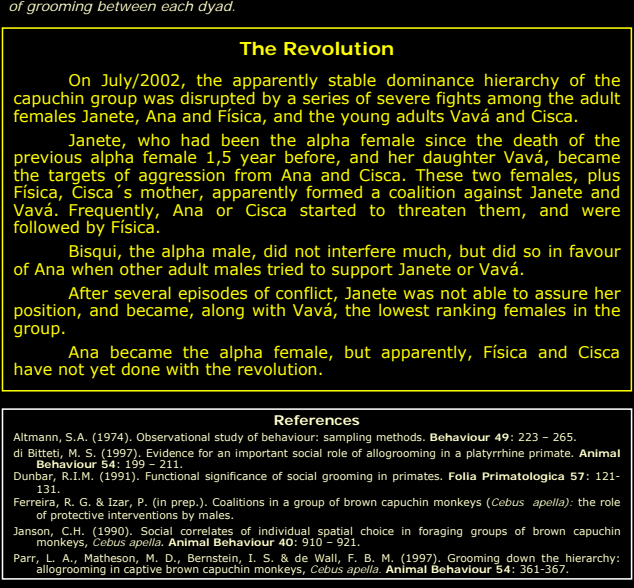